\title{
Effects of specimen size on fatigue life of metallic materials in high- cycle and very-high-cycle fatigue regimes
}

\author{
C. SUN, X. ZHANG, X. LIU and Y. HONG \\ State Key Laboratory of Nonlinear Mechanics, Institute of Mechanics, Chinese Academy of Sciences, Beijing, China
}

Received 20 October 2015; Accepted 18 Fanuary 2016; Published Online: 24 February 2016

\begin{abstract}
A B S TRACT This paper proposes a new method to investigate the effect of specimen size on fatigue life of metallic materials in high-cycle fatigue and very-high-cycle fatigue regimes in the light of statistical analysis. The performance of large specimen is correlated with that of small specimen via control volume (a high stress domain where potential fatigue crack initiation sites are located). The simulation results are in good agreement with a series of experimental data in high-cycle fatigue and very-high-cycle fatigue regimes from literature. The method is helpful for a quantitative estimation of fatigue life of large specimens from the experimental data of small specimens.
\end{abstract}

Keywords fatigue life; high-cycle fatigue; specimen size; very-high-cycle fatigue.

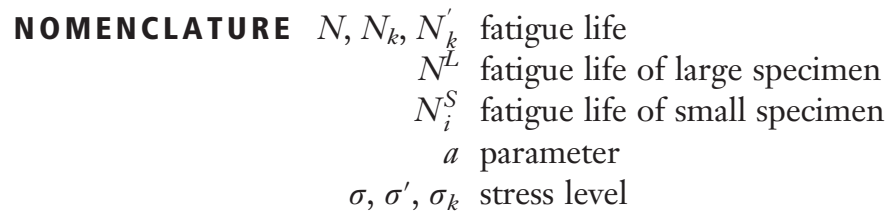

\section{INTRODUCTION}

The effect of specimen size on fatigue behaviour of materials is a topic of great importance in both scientific and engineering aspects. ${ }^{1-6}$ It is known that the fatigue strength of materials decreases with the increase of specimen size. Many investigations have indicated that the decrease in fatigue strength of large specimen is related to the high possibility of ineluctable presence of material defects and microstructure inhomogeneities. ${ }^{7-9}$ For example, Beretta et al. ${ }^{10}$ studied the scale effect in fatigue limit and crack growth rate for a high-strength steel used for high-speed railway axles and found that the average fatigue strength (for $90 \%$ survival probability) of full-scale specimens of railway axles is $25 \%$ lower than that of standard specimens (with diameter of $7.52 \mathrm{~mm}$ ) from several steel batches. Furuya ${ }^{11,12}$ investigated the effect of specimen size on very-high-cycle fatigue (VHCF) properties of high-strength steels via ultrasonic fatigue testing. In his results, the effect of specimen size was observed and large specimens showed lower fatigue strength due to the appearance of large inclusions in the fracture origin.

Correspondence: Y. Hong. E-mail: hongys@imech.ac.cn
The effect of specimen size on fatigue strength is classically taken into account by using the notch fatigue factor $K_{f}$, which is not always fully active in reducing the fatigue strength of components. ${ }^{2}$ Carpinteri et al. ${ }^{13}$ applied a fractal approach to explain the decrease of fatigue strength with the increase of specimen size by considering the fractal nature of the reacting crosssections of structures. Baz ant and Novák ${ }^{14}$ developed a probabilistic non-local theory for quasibrittle fracture initiation and size effect, in which the failure probability at a material point was assumed to be a power function (characterized by the Weibull modulus and scaling parameter) of the average stress in the neighbourhood. Shirani and Härkegård ${ }^{15}$ used the weakest-link method to evaluate the effect of specimen size on high-cycle fatigue (HCF) properties of EN-GJS-400-18-LT ductile cast iron and showed that the volume formulation of the weakest-link method yielded a better extrapolation than the surface formulation to obtain the $\mathrm{P}-\mathrm{S}-\mathrm{N}$ curve for large specimens. However, the results on EN-GJS-400-18 ductile cast iron by using the weakest-link approach indicated that the method worked well only in the case of specimens with different lengths. ${ }^{16}$ For high-strength steels, the fatigue failure usually initiates from the interior inclusions in the 
VHCF regime. Murakami et al. ${ }^{7}$ proposed the concept of control volume to interpret the decrease in fatigue strength under axial loading than that under rotating bending through the maximum inclusion within the control volume. The control volume is a high stress domain of a specimen, where fatigue crack initiation sites might be included. ${ }^{17}$ It is evident that the specimen under axial loading is more likely to have an inclusion as fracture origin than the specimen under rotating bending due to the larger control volume contained in the former case. However, the factors affecting the fatigue behaviour of materials are complicated, and the fatigue failure of materials may not be just induced by inclusions.

Fatigue tests usually consume plenty of time and expenses especially for large specimens and for the fatigue test in a large number of cycles. So, it is essential to develop a feasible method to estimate the effect of specimen size on fatigue behaviour of materials.

In this paper, a new method is developed for the effect of specimen size on fatigue life in view of statistical analysis. First, a procedure with limited number of fatigue test data is introduced for the $\mathrm{P}-\mathrm{S}-\mathrm{N}$ (probabilistic stress-life) curve prediction, which is applicable for the experimental data from different stress levels. Then, a second procedure is proposed for estimating the effect of specimen size on fatigue life. The predicted results are comparable with experimental data in $\mathrm{HCF}$ and VHCF regimes available in literature.

\section{A PROCEDURE FOR P-S-N CURVE PREDICTION}

\section{Formulation}

Considering that the $\mathrm{S}-\mathrm{N}$ curve is usually described as the form of $N=A \sigma^{a}$ in low-cycle fatigue and HCF regimes and that the fatigue strength of metallic materials continues to decrease with the increase of fatigue life in
VHCF regime, ${ }^{18-23}$ the fatigue life in relation to stress level is expressed as

$$
N=A_{i} \sigma^{a}
$$

where $A_{i}$ denotes the effect of other factors (such as the difference of specimens) except stress level.

From Eq. 1, the fatigue life $N_{k}$ under stress levels $\sigma_{k}(k=1,2, \ldots, n)$ is transformed to the fatigue life under an arbitrary given stress level $\sigma^{\prime}$, that is

$$
\begin{aligned}
N_{k}^{\prime}= & \frac{\sigma^{\prime a}}{\sigma_{k}^{a}} N_{k} \text { or } \log _{10} N_{k}^{\prime}=a \log _{10} \frac{\sigma^{\prime}}{\sigma_{k}}+\log _{10} \\
& N_{k}(k=1,2, \ldots, n)
\end{aligned}
$$

where the parameter $a$ is obtained by the least square regression for $\log _{10} N_{k}$ associated with $\log _{10} \sigma_{k}$.

\section{Distribution form of fatigue life}

The distribution form of fatigue life in VHCF for several high-strength steels is examined first. Figure 1 shows the fitting results of fatigue life for a high-carbon chromium steel from our previous experiment ${ }^{24}$ by normal distribution and Weibull distribution, respectively. Figure 2 shows the fitting results of fatigue life for a high-strength steel GCr15 by electroslag remelting from Ref. ${ }^{25}$ by normal distribution and Weibull distribution, respectively. The fitting results of both figures are derived via MATLAB (version 7.8.0) (MathWorks, Natick, MA, United States). For the fitting results by normal distribution, the coefficients of determination are 0.922 for Fig. 1a and 0.958 for Fig. 2a. While for the Weibull distribution, the coefficients of determination are 0.990 for Fig. $1 \mathrm{~b}$ and 0.923 for Fig. 2b. It is seen that the fatigue life in logarithm of base 10 in the VHCF regime approximately conforms to both normal and Weibull distributions.
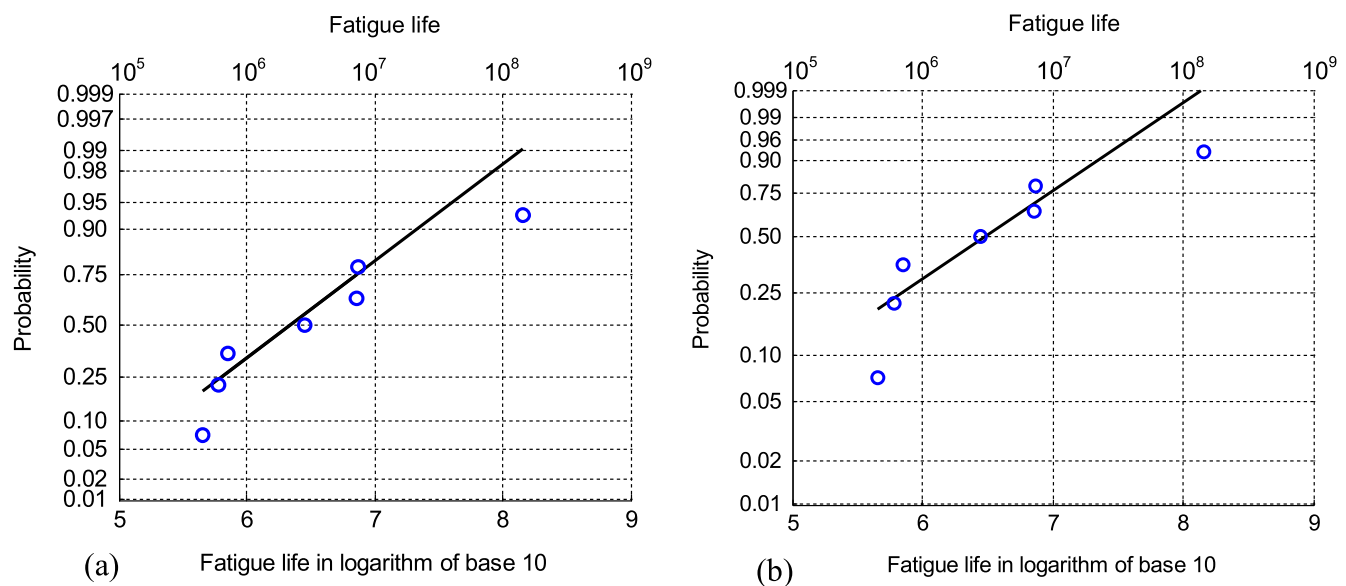

Fig. 1 Fitting results of fatigue life in logarithm of base 10 for a high-carbon chromium steel at $\sigma_{a}=860 \mathrm{MPa}$ from our previous experiment ${ }^{24}$ by (a) normal distribution and (b) Weibull distribution, respectively. 


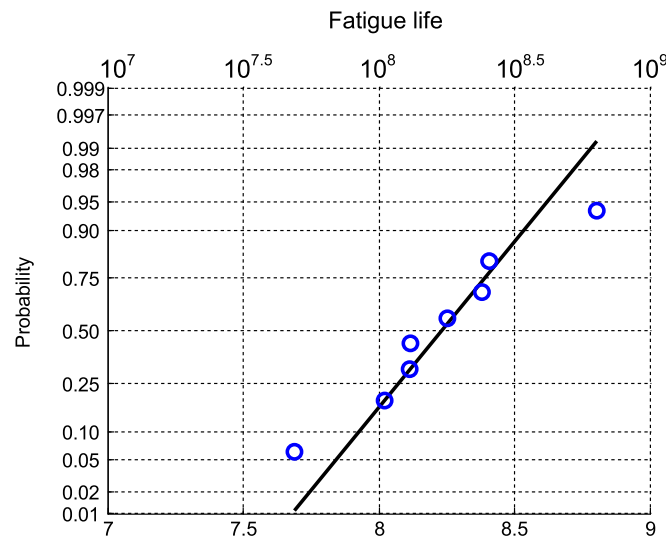

(a)

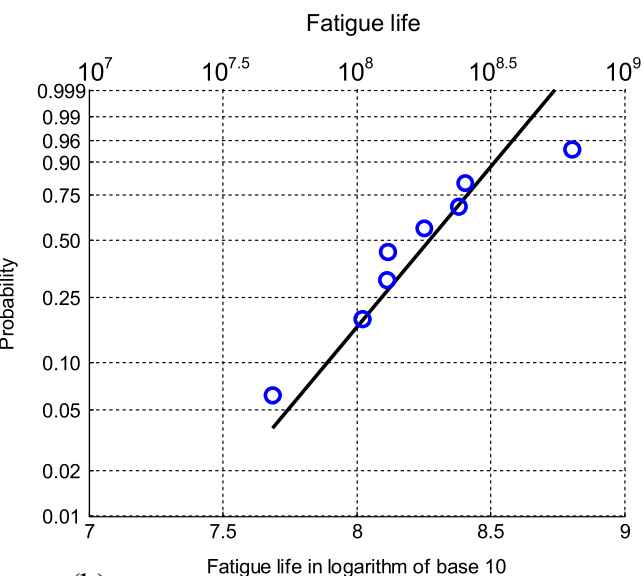

(b)

Fig. 2 Fitting results of fatigue life in logarithm of base 10 for a high-strength steel GCr15 by electroslag remelting at $\sigma_{a}=800 \mathrm{MPa}$ from literature ${ }^{25}$ by (a) normal distribution and (b) Weibull distribution, respectively.

\section{P-S-N curve prediction}

Figures 3-6 show the comparison of predicted P-S-N curves with experimental results for high-strength steels, aluminium alloys and titanium alloys. Here, the Weibull distribution is used for the fatigue life in logarithm of base 10 , where the scale parameter and the shape parameter are obtained by the maximum likelihood estimation via MATLAB (version7.8.0). In Fig. 4, the parameters are determined only by the experimental data (solid squares in Fig. 4) from Refs. ${ }^{19}$ and ${ }^{26}$. The fitting parameters for the Weibull distribution corresponding to different stress levels, that is, the parameters with which the fatigue life are calculated to obtain the $\mathrm{P}-\mathrm{S}-\mathrm{N}$ curves, are listed in Tables A1-A8 in the Appendix. It is seen in Figs 3-6 that almost all the experimental data are within the predicted $\mathrm{P}-\mathrm{S}-\mathrm{N}$ curves for $95 \%$ survival probability. This implies that the present method is capable of obtaining the P-S-N curve for both HCF and VHCF regimes. The predicted $\mathrm{P}-\mathrm{S}-\mathrm{N}$ curves by using the normal distribution for the fatigue life in logarithm of base 10 are also attempted and carried out with regard to the experimental data used in Figs 3-6. The comparisons indicate that the predicted $\mathrm{P}-\mathrm{S}-\mathrm{N}$ curves by Weibull distribution (Figs 3-6) are more conservative than those by normal distribution.

It is noted that for high-strength steels, the shape of the $\mathrm{S}-\mathrm{N}$ curve for VHCF often presents a duplex pattern corresponding to surface-initiated fracture mode and interior-initiated fracture mode..$^{20,26,27}$ Here, only the interior-initiated fracture mode is considered in Fig. 4.

\section{Comparison with conventional method}

For a further validation of the present method, Fig. 7 shows the comparison of predicted $\mathrm{P}-\mathrm{S}-\mathrm{N}$ curves by the present method with the experimental data tested by conventional testing method for a medium carbon

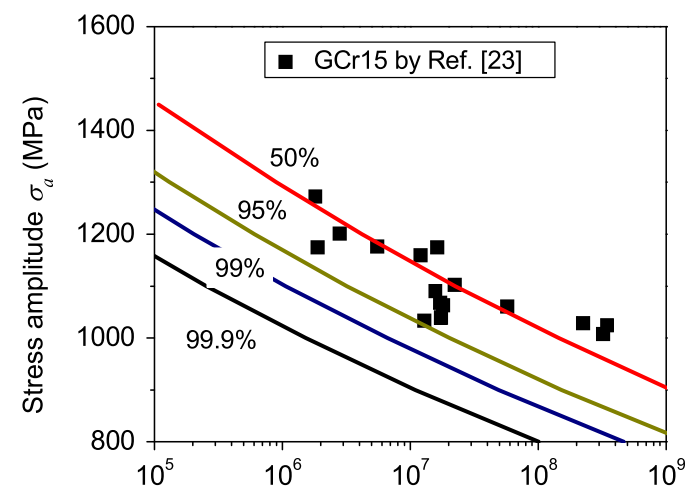

(a) Number of cycles to failure

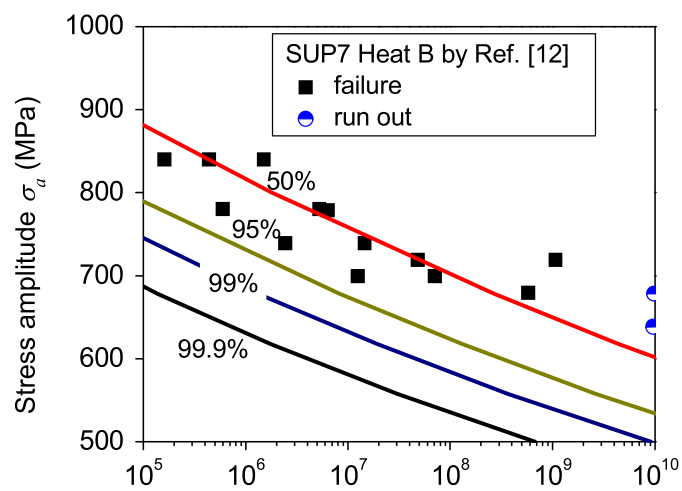

(b) Number of cycles to failure

Fig. 3 Comparison of predicted P-S-N curves with experimental results for high-strength steels. (a) Specimens of GCr15 under rotating bending test $(52.5 \mathrm{~Hz}, R=-1)^{23}$ and (b) specimens of JIS-SUP7 with $\phi 3 \mathrm{~mm}$ of Heat B under ultrasonic fatigue test $(20 \mathrm{kHz}, R=-1){ }^{12}$ 


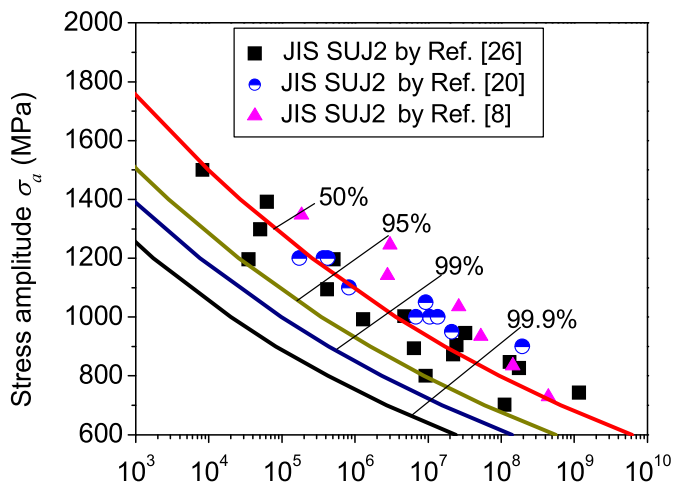

(a) Number of cycles to failure

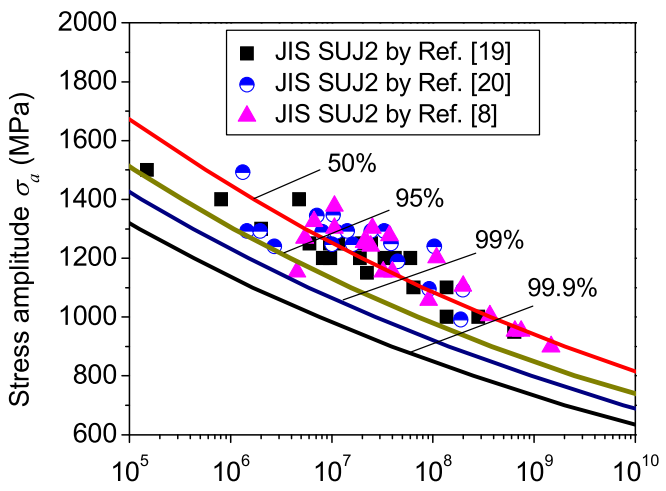

(b) Number of cycles to failure

Fig. 4 Comparison of predicted P-S-N curves with experimental results for high-strength steels (JIS SUJ2). ${ }^{8,19,20,26}$ (a) Axial loading test under conventional frequency, $R=-1$ and (b) rotating bending test under conventional frequency, $R=-1$.

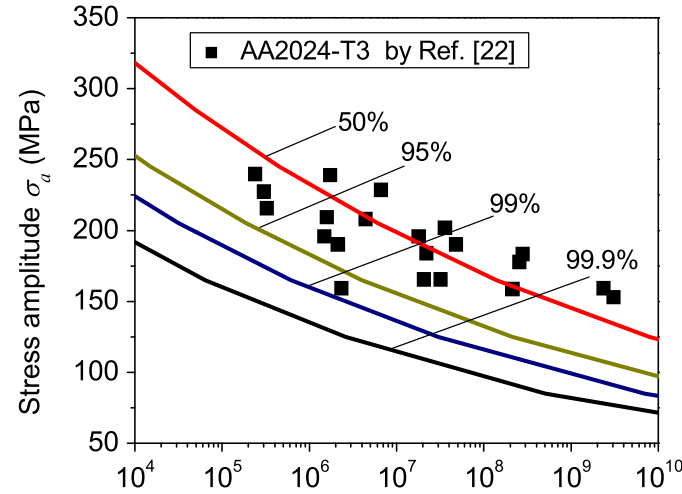

(a) Number of cycles to failure

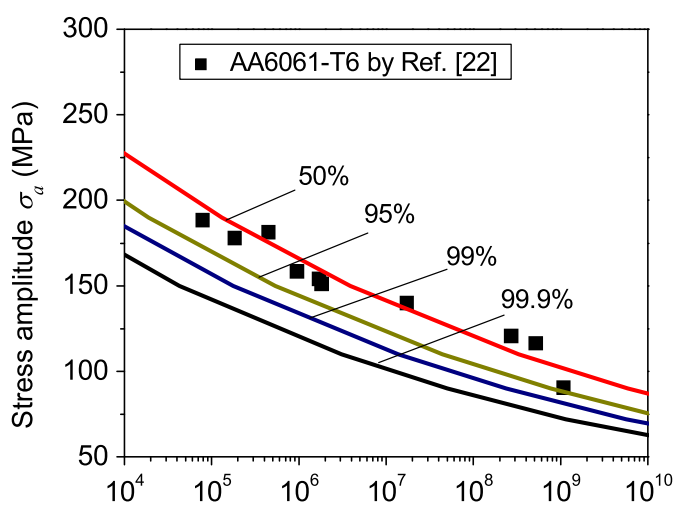

(b) Number of cycles to failure

Fig. 5 Comparison of predicted P-S-N curves with experimental results for aluminium alloys AA2024-T3 and AA6061-T6 by ultrasonic fatigue test $(20 \mathrm{kHz}, R=-1){ }^{22}$

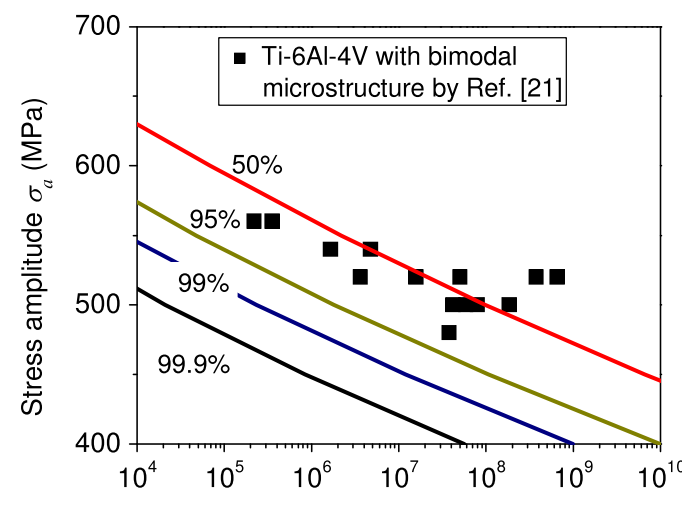

(a) Number of cycles to failure

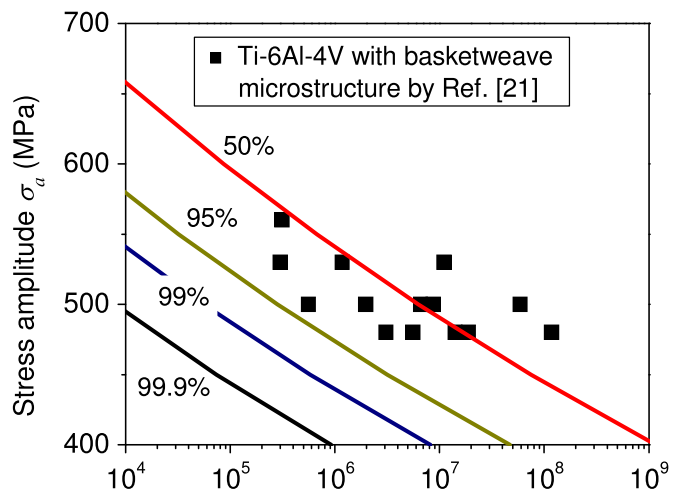

(b) Number of cycles to failure

Fig. 6 Comparison of predicted P-S-N curves with experimental results for Ti-6Al-4 V titanium alloy by ultrasonic fatigue test (20 kHz, $R=-1) .{ }^{21}$ (a) Bimodal microstructure and (b) basketweave microstructure. 


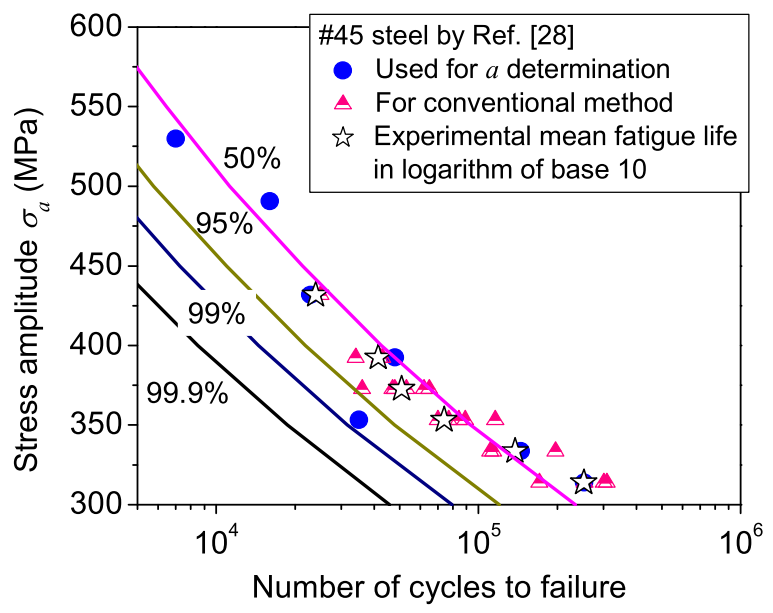

Fig. 7 Comparison of predicted P-S-N curves with experimental data by conventional testing method. ${ }^{28}$

steel (\#45 steel) in low cycle and HCF regimes. ${ }^{28}$ The value of parameter $a$ is determined only by a part of experimental data (solid circles in Fig. 7) with the maximum likelihood method ${ }^{28}$ except for the data under $372.78 \mathrm{MPa}$, and the fitting parameters for Weibull distribution corresponding to different stress levels are listed in Table A9 in the Appendix. It is seen in Fig. 7 that the predicted $\mathrm{P}-\mathrm{S}-\mathrm{N}$ curves in the present method are in good agreement with the experimental data.

\section{A PROCEDURE FOR PREDICTING THE EFFECT OF SPECIMEN SIZE ON FATIGUE LIFE}

\section{Formulation}

Many investigations have reported that the decrease of fatigue strength of large specimen is related to the high possibility of ineluctable presence of material defects and microstructure inhomogeneities. ${ }^{7,8,10-12}$ Thus, it is assumed that a large specimen is composed of a number of small specimens (with the same production procedure) in view of control volume and that the fatigue life for the large specimen under a certain stress level is the minimum fatigue life among $n$ small specimens under the same stress level similar to the concept of the weakest link in a chain, ${ }^{14,29}$ where $n$ is an integer presenting the ratio of the control volume for a large specimen to that for a small specimen.

Further, it is assumed that the fatigue life data for the small specimens $N_{i}^{S}(i=1,2, \ldots, n)$ in logarithm of base 10 under a certain stress level are independent random variables from the same Weibull distribution with the scale parameter $\lambda$ and the shape parameter $k$, that is, $F(x)=\left\{\begin{array}{ll}1-e^{-(x / \lambda)^{k}} & x \geq 0 \\ 0 & x<0\end{array}\right.$, then the cumulative distribution function of fatigue life in logarithm of base 10 for the large specimen $N^{L}$ under the same stress level is

$$
\begin{gathered}
F_{N^{L}}(x)=P\left\{N^{L} \leq x\right\} \\
=P\left\{\min \left\{N_{1}^{S}, N_{2}^{S}, \cdots, N_{n}^{S}\right\} \leq x\right\} \\
=1-P\left\{N_{1}^{S}>x\right\} P\left\{N_{2}^{S}>x\right\} \cdots P\left\{N_{n}^{S}>x\right\} \\
=1-[1-F(x)]^{n} \\
= \begin{cases}1-e^{-\left(x n^{1 / k} / \lambda\right)^{k}} & x \geq 0 \\
0 & x<0\end{cases}
\end{gathered}
$$

Equation 3 indicates that the fatigue life in logarithm of base 10 for the large specimen under a certain stress level conforms to a pattern of Weibull distribution with
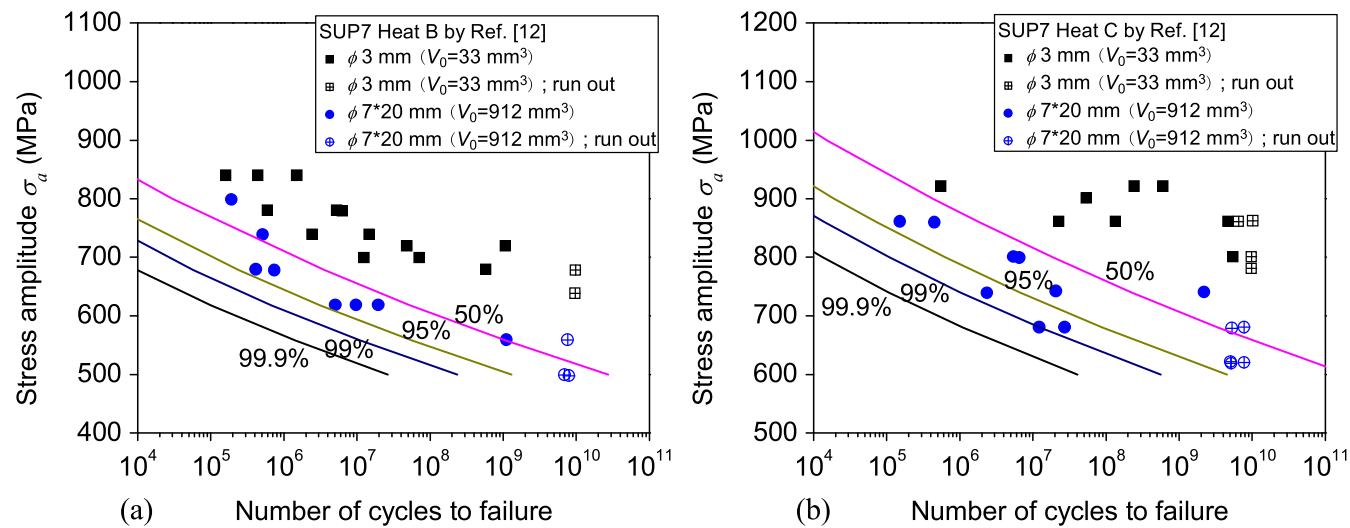

Fig. 8 Comparison of predicted P-S-N curves from small specimens $(\phi 3 \mathrm{~mm})$ with experimental data for a spring steel (JIS-SUP7). ${ }^{12}$ (a) Specimens with $\phi 7 \times 20 \mathrm{~mm}$ of Heat B and (b) specimens with $\phi 7 \times 20 \mathrm{~mm}$ of Heat C. 

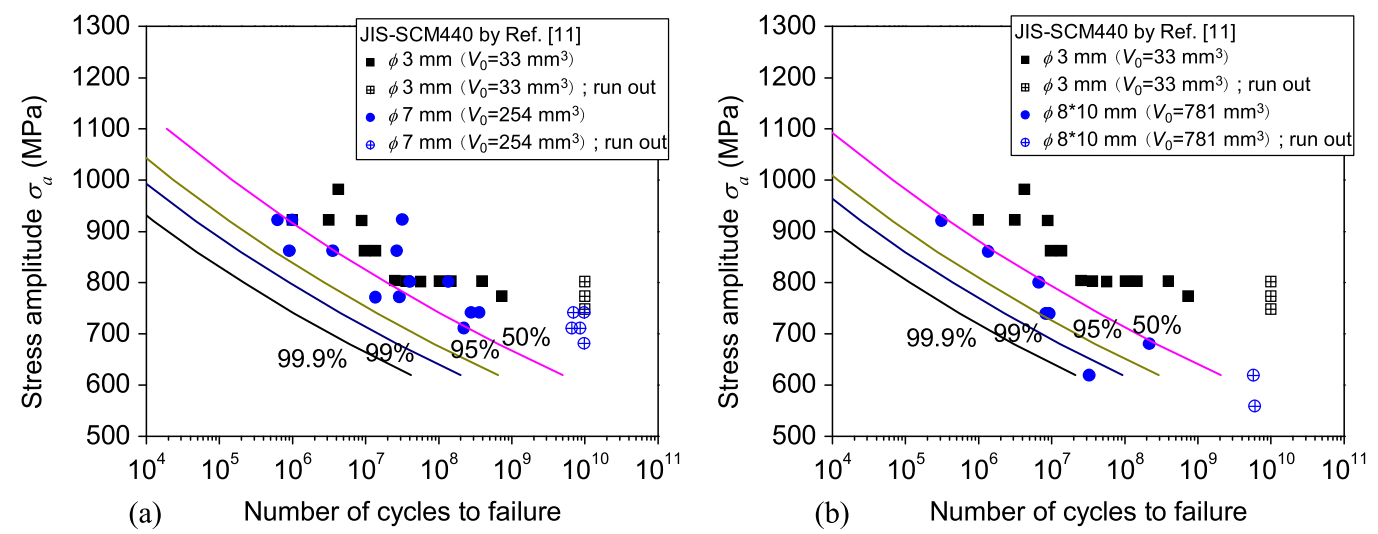

Fig. 9 Comparison of predicted P-S-N curves from small specimens $(\phi 3 \mathrm{~mm}$ ) with experimental data for a low-alloy steel JIS-SCM440 (AISI4140). ${ }^{11}$ (a) Specimens with $\phi 7 \mathrm{~mm}$ and (b) specimens with $\phi 8 \times 10 \mathrm{~mm}$.

the scale parameter $\lambda / n^{1 / k}$ and the shape parameter $k$. It also indicates that the fatigue life of a large specimen has the same distribution form as that of a small specimen; that is, the distribution form of fatigue life is irrespective of specimen size.

\section{Comparison with experimental results}

Figure 8 shows the comparison of predicted $\mathrm{P}-\mathrm{S}-\mathrm{N}$ curves from small specimens $(\phi 3 \mathrm{~mm})$ with experimental data for a spring steel (JIS-SUP7) under ultrasonic fatigue test $(20 \mathrm{kHz}, R=-1)$, and Fig. 9 shows the comparison for a low-alloy steel JISSCM440 (AISI-4140). In Figs 8 and 9, $V_{0}$ denotes the control volume determined by the region subjected to larger than $90 \%$ of the maximum stress. ${ }^{12}$ For the specimen with $\phi 7 \times 20 \mathrm{~mm}$ (cylindrical type specimen with $7 \mathrm{~mm}$ in diameter and $20 \mathrm{~mm}$ in length for the gauge section), the value of $V_{0}$ is about 28 times of that for the specimen with $\phi 3 \mathrm{~mm}$ (hourglass-type specimen with $3 \mathrm{~mm}$ in diameter for the minimum gauge section). For the specimen with $\phi$ $7 \mathrm{~mm}$ (hourglass-type specimen) and for the specimen with $\phi 8 \times 10 \mathrm{~mm}$ (cylindrical-type specimen), the value of $V_{0}$ is about eight times and 24 times of that for the specimen with $\phi 3 \mathrm{~mm}$, respectively. The fitting parameters for the Weibull distribution corresponding to different stress levels in Figs 8 and 9 are listed in Tables A10-A13 in the Appendix. Additionally, in Fig. 8, Heat B denotes the steel that tends to contain only oxide-type inclusions at the internal fracture origin of specimen and Heat C denotes the one that tends to contain TiN inclusions and matrix as well as the oxide-type inclusions. ${ }^{12}$

It is seen that the present method reflects the effect of specimen size on fatigue life. For example, for specimens with $\phi 7 \times 20 \mathrm{~mm}$ in Fig. $8 \mathrm{a}$, the estimated values of fatigue strength for $50 \%$ and $95 \%$ survival probability at $10^{7}$ cycles are about $14 \%$ and $12 \%$ lower than those of small specimens with $\phi 3 \mathrm{~mm}$, respectively. The present method provides an estimation of the fatigue life for a large specimen through the experimental data tested with a small specimen.

\section{Estimation of fatigue life for full-scale specimens of railway axles}

For a further discussion of the present method in potential application, the fatigue life of full-scale specimens of railway axles (EA4T railway axle steel) is estimated by using the fatigue data tested with the small specimens cut from the real railway axles. The main chemical compositions of this steel are $0.25 \mathrm{C}$, $0.95 \mathrm{Cr}, 0.65 \mathrm{Mn}, 0.30 \mathrm{Si}, 0.20 \mathrm{Mo}, 0.012 \mathrm{P}$ and $0.010 \mathrm{~S}$ in mass percentage (Fe balance). The average tensile strength is $674 \mathrm{MPa}$, and the average yield strength is $519 \mathrm{MPa}$ from the tensile test of three cylindrical specimens with the diameter of $6 \mathrm{~mm}$ by an MTS 810 testing machine. The shape of small specimens is shown in Fig. 10, which is tested via a rotating bending method. Before fatigue testing, the round notch surface was ground and polished to eliminate machine scratches. The shape of full-scale railway axle is shown in Fig. 11.

For bending loading, crack initiation sites are likely to be at the surface and in the vicinity of the surface of the specimen. For the present small specimens tested via rotating bending, they all failed from the surface. So, the critical part of the specimen surface with a certain thickness $h$, for which $\sigma \geq 0.9 \sigma_{0}$ in Ref. ${ }^{17}\left(\sigma_{0}\right.$ is the maximum stress at the smallest cross-section of the specimen) is considered as the control volume, that is 


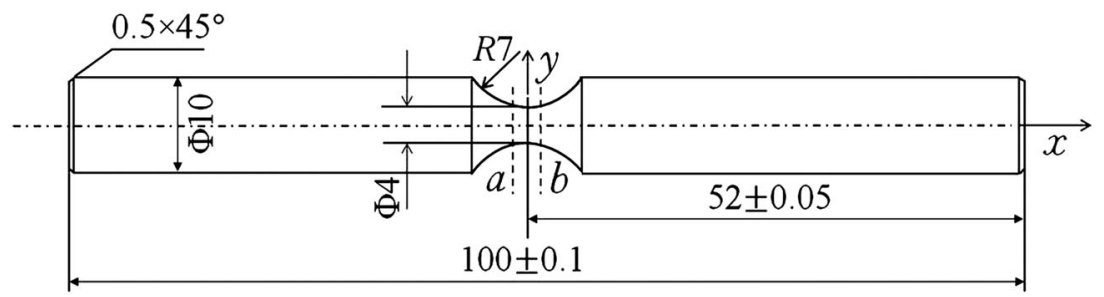

Fig. 10 Geometry of small specimen, dimensions in millimetre.

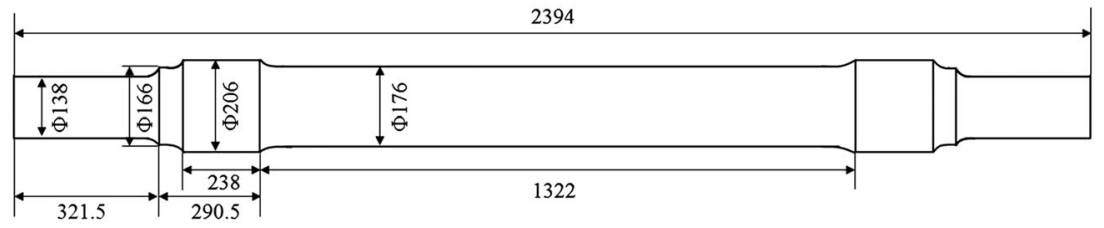

Fig. 11 Geometry of full-scale specimen, dimensions in millimetre.

$$
\begin{gathered}
V_{S}=\int_{a}^{b}\left[\pi y^{2}-\pi(y-b)^{2}\right] \mathrm{d} x \\
=\int_{a}^{b}\left[2 \pi y b-\pi b^{2}\right] \mathrm{d} x \\
=2 \pi b \int_{a}^{b}\left(R+\frac{d}{2}-\sqrt{R^{2}-x^{2}}\right) \mathrm{d} x-\pi(b-a) b^{2} \\
=2 \pi h\left(R+\frac{d}{2}\right)(b-a)-\pi b\left(b \sqrt{R^{2}-b^{2}}-a \sqrt{R^{2}-a^{2}}\right) \\
-\pi h R^{2}\left(\arcsin \frac{b}{R}-\arcsin \frac{a}{R}\right)-\pi(b-a) b^{2}
\end{gathered}
$$

where $R$ is the radius of specimen notch, $d$ is the diameter of the smallest section and $a$ and $b$ denote the position of the cross-section where $\sigma=0.9 \sigma_{0}$ as shown in Fig. 10 .

For the present small specimens shown in Fig. 10, $R=7 \mathrm{~mm}, d=4 \mathrm{~mm}, a=-0.891 \mathrm{~mm}, b=1.115 \mathrm{~mm}$ and $b$ is taken as $0.05 \mathrm{~mm}$ (for the crack initiation sites at the surface and in the vicinity of the surface of the specimen, the value of $b$ is quite small and has little influence on the final calculated fatigue life of large specimens); thus, the control volume is calculated as $V_{S}=1.260 \mathrm{~mm}^{3}$.

For the full-scale railway axle, the body of the axle is subjected to the largest bending load. The value of $b$ is also taken as $0.05 \mathrm{~mm}$, and the control volume for the full-scale railway axle is $V_{L}=3.14 \times 176 \times 1322 \times 0.05=$ $36529.5 \mathrm{~mm}^{3}$.

Figure 12 shows the estimated $\mathrm{P}-\mathrm{S}-\mathrm{N}$ curves for the full-scale railway axle from experimental data of small specimens under rotating bending test, and the fitting parameters for Weibull distribution corresponding to different stress levels are listed in Tables A14 and A15 in the Appendix. It is seen that the fatigue strength of the full-scale railway axles is substantially decreased

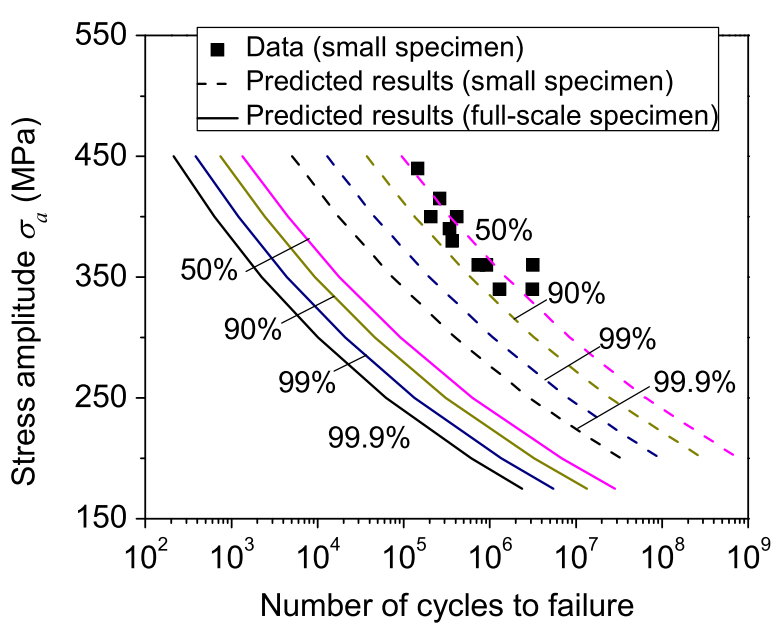

Fig. 12 Predicted P-S-N curves for full-scale railway axle $\left(V_{\mathrm{L}}=36529.5 \mathrm{~mm}^{3}\right)$ from the experimental data of small specimen $\left(V_{\mathrm{S}}=1.260 \mathrm{~mm}^{3}\right)$ under rotating bending test $(52.5 \mathrm{~Hz}, R=-1)$.

because of the large control volume compared with that of the small specimens. For example, at the fatigue life of $10^{6}$ cycles, the estimated fatigue strength for $50 \%$ and $90 \%$ survival probability of full-scale railway axles is $34 \%$ and $33 \%$ lower than that of the small specimens (with the minimum diameter of $4 \mathrm{~mm}$ ). This is in reasonable agreement with the experimental data that the fatigue limit of full-scale railway axles (EA4T) is 30\% lower than that of specimens with a diameter of $10 \mathrm{~mm}$ in Ref. ${ }^{30}$ and that the average fatigue strength (for $90 \%$ survival probability) of full-scale railway axles (30NiCrMoV12) is $25 \%$ lower than that of standard specimens (with a diameter of $7.52 \mathrm{~mm}$ ) of several batches under four-point bending test in Ref. ${ }^{10}$. 
It should be noted that for the cases in this paper, the Weibull distribution is suitable for the fitting of the fatigue life data for small specimens in logarithm of base 10 and that such type of distribution is used for describing the fatigue life data, for which an explicit distribution can be derived for the fatigue life of relevant large specimens. However, for other cases that another distribution, for example, normal distribution is more suitable for the fitting and is chosen for describing the fatigue life of small specimens, an explicit distribution may not be obtained for the fatigue life of relevant large specimens. For such latter cases, the $\mathrm{P}-\mathrm{S}-\mathrm{N}$ curves for large specimens can be produced via the statistics analysis of the fatigue life calculated by Monte Carlo method.

\section{CONCLUSIONS}

In this paper, a new method is developed for studying the effect of specimen size on fatigue life by the approach of statistical analysis, which is combined with the control volume concept with respect to large and small specimens. The method reflects the effect of specimen size on fatigue life and is capable of estimating the fatigue life of large specimen with limited number of experimental data from small specimens. For the case of a spring steel JIS-SUP7 and a low-alloy steel JIS-SCM440 (AISI4140), the experimental data for the large specimens are almost within the estimated $\mathrm{P}-\mathrm{S}-\mathrm{N}$ curve for $99 \%$ survival probability from small specimens. For the case of railway axles, at the fatigue life of $10^{6}$ cycles, the estimated fatigue strength for $90 \%$ survival probability of full-scale railway axles is $33 \%$ lower than that of the small specimens with the minimum diameter of $4 \mathrm{~mm}$, which is comparable with the experimental result that the fatigue limit of full-scale railway axles is $30 \%$ lower than that of the small specimens with the diameter of $10 \mathrm{~mm}$.

\section{Acknowledgements}

The authors gratefully acknowledge the support of the $\mathrm{Na}-$ tional Basic Research Program of China (2012CB937500) and the National Natural Science Foundation of China (11572325 and 11202210).

\section{REFERENCES}

1 Makino, T., Kato, T. and Hirakawa, K. (2011) Review of the fatigue damage tolerance of high-speed railway axles in Japan. Eng. Fract. Mech., 78, 810-825.

2 Zerbst, U., Beretta, S., KÖhler, G., Lawton, A., Vormwald, M., Beier, H. T., Klinger, C., C`erný, I., Rudlin, J., Heckel, T. and
Klingbeil, D. (2013) Safe life and damage tolerance aspects of railway axles - a review. Eng. Fract. Mech., 98, 214-271.

3 Fricke, W. and Feltz, O. (2013) Consideration of influence factors between small-scale specimens and large components on the fatigue strength of thin-plated block joints in shipbuilding. Fatigue Fract. Eng. Mater. Struct., 36, 1223-1231.

4 Lei, Z., Xie, J., Sun, C. and Hong, Y. (2014) Effect of loading condition on very-high-cycle fatigue behavior and dominant variable analysis. Sci. China-Phys. Mech. Astron., 57, 74-82.

5 Paolino, D. S., Tridello, A., Chiandussi, G. and Rossetto, M. (2014) On specimen design for size effect evaluation in ultrasonic gigacycle fatigue testing. Fatigue Fract. Eng. Mater. Struct., 37, 570-579.

6 Fajkoš, R., Zima, R. and Strnadel, B. (2015) Fatigue limit of induction hardened railway axles. Fatigue Fract. Eng. Mater. Struct., 38, 1255-1264.

7 Murakami, Y., Yokoyama, N. N. and Nagata, J. (2002) Mechanism of fatigue failure in ultralong life regime. Fatigue Fract. Eng. Mater. Struct., 25, 735-746.

8 Nakajima, M., Tokaji, K., Itoga, H. and Shimizu, T. (2010) Effect of loading condition on very high cycle fatigue behavior in a high strength steel. Int. F. Fatigue, 32, 475-480.

9 Matsunaga, H., Sun, C., Hong, Y. and Murakami, Y. (2015) Dominant factors for very-high-cycle fatigue of high-strength steels and a new design method for components. Fatigue Fract. Eng. Mater. Struct., 38, 1274-1284.

10 Beretta, S., Ghidini, A. and Lombardo, F. (2005) Fracture mechanics and scale effects in the fatigue of railway axles. Eng. Fract. Mech., 72, 195-208.

11 Furuya, Y. (2010) Size effects in gigacycle fatigue of highstrength steel under ultrasonic fatigue testing. Procedia Engineering, 2, 485-490.

12 Furuya, Y. (2011) Notable size effects on very high cycle fatigue properties of high-strength steel. Mater. Sci. Eng. A, 528, 5234-5240.

13 Carpinteri, A., Spagnoli, A. and Vantadori, S. (2009) Size effect in S-N curves: a fractal approach to finite-life fatigue strength. Int. F. Fatigue, 31, 927-933.

14 Baz ant, Z. P. and Novák, D. (2000) Probabilistic nonlocal theory for quasibrittle fracture initiation and size effect. I: theory. 7. Eng. Mech-ASCE, 126, 166-174.

15 Shirani, M. and Härkegård, G. (2011) Fatigue life distribution and size effect in ductile cast iron for wind turbine components. Eng. Fail. Anal., 18, 12-24.

16 Cova, M., Nanni, M. and Tovo, R. (2014) Geometrical size effect in high cycle fatigue strength of heavy-walled ductile cast iron GJS400: weakest link vs defect-based approach. Procedia Engineering, 74, 101-104.

17 Murakami, Y. (2002) Metal Fatigue: Effects of Small Defects and Nonmetallic Inclusions, Elsevier Science Ltd.: Oxford.

18 Murakami, Y., Nomoto, T. and Ueda, T. (2000) On the mechanism of fatigue failure in the superlong life regime ( $N>10^{7}$ cycles). Part I: influence of hydrogen trapped by inclusions. Fatigue Fract. Eng. Mater. Struct., 23, 893-902.

19 Shiozawa, K., Lu, L. and Ishihara, S. (2001) $S-N$ curve characteristics and subsurface crack initiation behaviour in ultra-long life fatigue of a high carbon-chromium bearing steel. Fatigue Fract. Eng. Mater. Struct., 24, 781-790.

20 Sakai, T., Sato, Y. and Oguma, N. (2002) Characteristic S-N properties of high-carbon-chromium-bearing steel under axial loading in long-life fatigue. Fatigue Fract. Eng. Mater. Struct., 25, 765-773.

21 Zuo, J. H., Wang, Z. G. and Han, E. H. (2008) Effect of microstructure on ultra-high cycle fatigue behavior of Ti-6Al-4 V. Mater. Sci. Eng. A, 473, 147-152. 
22 Wang, Q. Y., Li, T. and Zeng, X. G. (2010) Gigacycle fatigue behavior of high strength aluminum alloys. Procedia Engineering, 2, 65-70.

23 Hong, Y., Zhao, A., Qian, G. and Zhou, C. (2012) Fatigue strength and crack initiation mechanism of very-high-cycle fatigue for low alloy steels. Metall. Mater. Trans. A, 43, 2753-2762.

24 Sun, C., Lei, Z., Xie, J. and Hong, Y. (2013) Effects of inclusion size and stress ratio on fatigue strength for high-strength steels with fish-eye mode failure. Int. F. Fatigue, 48, 19-27.

25 Li, Y. D., Yang, Z. G., Li, S. X., Liu, Y. B. and Chen, S. M. (2008) Correlations between very high cycle fatigue properties and inclusions of GCr15 bearing Steel. Acta Metall. Sin., 44, 968-972.

26 Shiozawa, K., Hasegawa, T., Kashiwagi, Y. and Lu, L. (2009) Very high cycle fatigue properties of bearing steel under axial loading condition. Int. 7. Fatigue, 31, 880-888.

27 Li, W., Sakai, T., Li, Q., Lu, L. T. and Wang, P. (2010) Reliability evaluation on very high cycle fatigue property of GCr15 bearing steel. Int. F. Fatigue, 32, 1096-1107.

28 Ling, J. and Pan, J. (1997) A maximum likelihood method for estimating $P-S-N$ curves. Int. 7. Fatigue, 19, 415-419.

29 Weibull, W. and Sweden, S. (1951) A statistical distribution function of wide applicability. ASME 7. Appl. Mech., 18, 293-297.

30 Linhart, V., Auředník, A., Furbacher, I., černý, I., Zima, R., Matušek, P. and Novosad, M. (2003) Experimental modelling and evaluation of fatigue strength and damage mechanisms of railway axles and wheels. In: Proceeding of International Seminar on Railway Axles (Edited by R. A. Smith), Imperial College London: UK.

\section{Appendix}

Table A1 Fitting parameters of Weibull distribution in Fig. 3a

\begin{tabular}{lcc}
\hline Stress amplitude $(\mathrm{MPa})$ & Scale parameter & Shape parameter \\
\hline 1450 & 5.16 & 14.58 \\
1300 & 6.08 & 17.23 \\
1200 & 6.75 & 19.16 \\
1100 & 7.48 & 21.27 \\
1000 & 8.29 & 23.58 \\
900 & 9.17 & 26.13 \\
800 & 10.16 & 28.98 \\
\hline
\end{tabular}

Table A2 Fitting parameters of Weibull distribution in Fig. 3b

Stress amplitude $(\mathrm{MPa})$ Scale parameter Shape parameter

\begin{tabular}{lcc}
\hline 900 & 4.94 & 7.62 \\
800 & 6.49 & 9.95 \\
678 & 8.67 & 13.21 \\
618 & 9.88 & 15.03 \\
558 & 11.22 & 17.03 \\
500 & 12.66 & 19.18 \\
\hline
\end{tabular}

Table A3 Fitting parameters of Weibull distribution in Fig. 4a

\begin{tabular}{lcc}
\hline Stress amplitude (MPa) & Scale parameter & Shape parameter \\
\hline 1800 & 2.99 & 6.60 \\
1500 & 4.15 & 9.36 \\
1400 & 4.59 & 10.40 \\
1200 & 5.57 & 12.72 \\
1000 & 6.72 & 15.45 \\
900 & 7.39 & 17.02 \\
800 & 8.13 & 18.78 \\
700 & 8.97 & 20.78 \\
600 & 9.95 & 23.08 \\
\hline
\end{tabular}

Table A4 Fitting parameters of Weibull distribution in Fig. 4b

\begin{tabular}{ccc} 
Stress amplitude (MPa) & Scale parameter & Shape parameter \\
\hline 1700 & 4.99 & 16.96 \\
1500 & 5.86 & 19.95 \\
1400 & 6.34 & 21.60 \\
1300 & 6.85 & 23.38 \\
1200 & 7.41 & 25.29 \\
1100 & 8.01 & 27.37 \\
1000 & 8.68 & 29.65 \\
900 & 9.41 & 32.16 \\
800 & 10.23 & 34.98 \\
700 & 11.15 & 38.17 \\
600 & 12.23 & 41.85 \\
\hline
\end{tabular}

Table A5 Fitting parameters of Weibull distribution in Fig. 5a

Stress amplitude (MPa) Scale parameter Shape parameter

\begin{tabular}{lcc}
\hline 325 & 4.11 & 5.81 \\
285 & 4.94 & 7.11 \\
245 & 5.90 & 8.59 \\
205 & 7.03 & 10.32 \\
165 & 8.39 & 12.41 \\
125 & 10.14 & 15.09 \\
85 & 12.57 & 18.80 \\
45 & 16.56 & 24.90 \\
\hline
\end{tabular}

Table A6 Fitting parameters of Weibull distribution in Fig. 5b

\begin{tabular}{lcc} 
Stress amplitude $(\mathrm{MPa})$ & Scale parameter & Shape parameter \\
\hline 230 & 4.05 & 11.13 \\
190 & 5.25 & 14.46 \\
150 & 6.72 & 18.58 \\
110 & 8.65 & 23.98 \\
90 & 9.90 & 27.47 \\
72 & 11.29 & 31.35 \\
50 & 13.56 & 37.70 \\
\hline
\end{tabular}


Table A7 Fitting parameters of Weibull distribution in Fig. 6a

\begin{tabular}{ccc}
\hline Stress amplitude (MPa) & Scale parameter & Shape parameter \\
\hline 650 & 3.7 & 4.85 \\
600 & 5.11 & 6.63 \\
550 & 6.62 & 8.55 \\
500 & 8.27 & 10.63 \\
450 & 10.1 & 12.94 \\
400 & 12.1 & 15.51 \\
\hline
\end{tabular}

Table A8 Fitting parameters of Weibull distribution in Fig. 6b

\begin{tabular}{lcc}
\hline Stress amplitude $(\mathrm{MPa})$ & Scale parameter & Shape parameter \\
\hline 670 & 4.02 & 6.72 \\
600 & 5.15 & 8.63 \\
550 & 6.04 & 10.14 \\
500 & 7.01 & 11.78 \\
450 & 8.09 & 13.59 \\
400 & 9.28 & 15.61 \\
\hline
\end{tabular}

Table A9 Fitting parameters of Weibull distribution in Fig. 7

\begin{tabular}{ccc}
\hline Stress amplitude $(\mathrm{MPa})$ & Scale parameter & Shape parameter \\
\hline 600 & 3.62 & 30.92 \\
550 & 3.85 & 32.89 \\
500 & 4.09 & 35.04 \\
450 & 4.37 & 37.42 \\
400 & 4.67 & 40.08 \\
350 & 5.01 & 43.09 \\
300 & 5.41 & 46.57 \\
\hline
\end{tabular}

Table A10 Fitting parameters of Weibull distribution in Fig. 8a

\begin{tabular}{lcc}
\hline Stress amplitude (MPa) & Scale parameter & Shape parameter \\
\hline 900 & 3.19 & 7.62 \\
800 & 4.64 & 9.95 \\
678 & 6.74 & 13.21 \\
618 & 7.92 & 15.03 \\
558 & 9.23 & 17.03 \\
500 & 10.64 & 19.18 \\
\hline
\end{tabular}

Table A11 Fitting parameters of Weibull distribution in Fig. 8b

\begin{tabular}{lcc}
\hline Stress amplitude $(\mathrm{MPa})$ & Scale parameter & Shape parameter \\
\hline 1120 & 2.86 & 5.65 \\
1000 & 4.39 & 7.65 \\
900 & 5.85 & 9.49 \\
860 & 6.49 & 10.28 \\
800 & 7.50 & 11.53 \\
740 & 8.59 & 12.88 \\
680 & 9.78 & 14.35 \\
600 & 11.56 & 16.51 \\
\hline
\end{tabular}

Table A12 Fitting parameters of Weibull distribution in Fig. 9a

\begin{tabular}{lcc}
\hline Stress amplitude (MPa) & Scale parameter & Shape parameter \\
\hline 1100 & 4.40 & 13.09 \\
1000 & 5.30 & 15.44 \\
920 & 6.09 & 17.49 \\
860 & 6.73 & 19.14 \\
800 & 7.42 & 20.92 \\
740 & 8.15 & 22.83 \\
680 & 8.95 & 24.90 \\
620 & 9.83 & 27.17 \\
\hline
\end{tabular}

Table A13 Fitting parameters of Weibull distribution in Fig. 9b

\begin{tabular}{lcc}
\hline Stress amplitude (MPa) & Scale parameter & Shape parameter \\
\hline 1100 & 4.04 & 13.09 \\
1000 & 4.94 & 15.44 \\
920 & 5.72 & 17.49 \\
860 & 6.35 & 19.14 \\
800 & 7.04 & 20.92 \\
740 & 7.77 & 22.83 \\
680 & 8.56 & 24.90 \\
620 & 9.44 & 27.17 \\
\hline
\end{tabular}

Table A14 Fitting parameters of Weibull distribution for small specimens in Fig. 12

\begin{tabular}{ccc}
\hline Stress amplitude (MPa) & Scale parameter & Shape parameter \\
\hline 450 & 5.06 & 22.16 \\
400 & 5.62 & 24.62 \\
350 & 6.27 & 27.41 \\
300 & 7.01 & 30.64 \\
250 & 7.89 & 34.45 \\
200 & 8.97 & 39.11 \\
\hline
\end{tabular}

Table A15 Fitting parameters of Weibull distribution for full-scale specimens in Fig. 12

\begin{tabular}{ccc}
\hline Stress amplitude (MPa) & Scale parameter & Shape parameter \\
\hline 450 & 3.18 & 22.16 \\
400 & 3.71 & 24.62 \\
350 & 4.31 & 27.41 \\
300 & 5.02 & 30.64 \\
250 & 5.86 & 34.45 \\
200 & 6.90 & 39.11 \\
175 & 7.52 & 41.91 \\
\hline
\end{tabular}

